\title{
Total cost model for disposal of living garbage
}

\author{
Jingmei Yang \\ School of mathematics and statistics, Qujing Normal University, Qujing, Yunnan \\ 421327416@qq.com
}

Keywords: total cost analysis, analytic hierarchy process, positive reciprocal matrix.

\begin{abstract}
In recent years, many cities in our country have been surrounded by garbage, and the output of domestic garbage has soared. As a result, the associated disposal capacity fails to meet requirements and the environmental pollution is serious. Under this background, this article is based on the principle of "reduction, recycling and harmlessness" in conformity with the principle of ensuring public health and human health and preventing environmental pollution. From the three aspects of business costs, technical costs, indirect current and long-term social costs, an analysis model of the total costs of living garbage disposal is set up, and costs on various aspects are detailed as the items: the business costs covering the collection costs, transportation costs, processing costs; technical costs including variable costs, fixed costs, losses of pollution to human health and life are treated as indirect current and long-term social costs; and then analysis model for the total cost required by living garbage disposal in China is further obtained.
\end{abstract}

\section{Problem restatement and analysis}

In September 2017, the Central Environmental Protection Inspection Group carried out environment inspection in various provinces in China, marking a new stage of environmental governance in China. In recent years, many cities in our country have been surrounded by garbage, and the output of domestic garbage has soared. As a result, the associated disposal capacity fails to meet requirements and the environmental pollution is serious. Environmental problems have not only become a problem of China's sustainable development, but have also now a devil that has swallowed up economic achievements. According to relevant statistics, the cultivated land and homes of nearly 400 million people in 471 counties in 18 provinces and autonomous regions in China are suffering from varying degrees of desertification. And desertification is still growing at a rate of over 10,000 square kilometers each year. Therefore, the environmental governance is very urgent, the primary and foremost task is to establish the required cost model for garbage disposal.

\section{Symbol description}

Total social costs for processing of living garbage $\mathrm{A}$; business costs $\mathrm{B}_{1}$; technological costs $\mathrm{B}_{2}$; social costs $B_{3}$; collection costs $C_{1}$; transportation costs $C_{2}$; disposal costs $C_{3}$; variable costs $D_{1}$; fixed costs $\mathrm{D}_{2}$; loss incurred from water pollution $\mathrm{F}_{1}$; loss incurred from air pollution $\mathrm{F}_{2}$; loss incurred from solid waste pollution $\mathrm{F}_{3}$;

\section{Building and solving of the model}

\subsection{Building of the model}

The total social costs of living garbage disposal are divided into three parts: business costs, 
technical costs and long-term social costs, as shown in Figure 1: Business costs analysis: business costs cover the three aspects, namely collection costs, transportation costs, disposal costs, as shown in Figure 2:

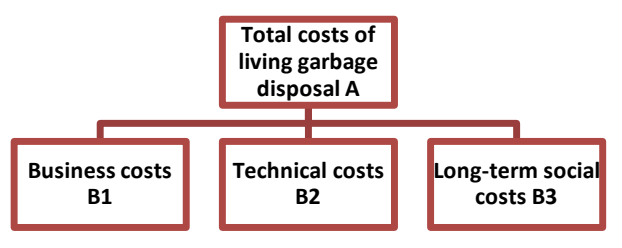

Fig.1 Components of the total social costs for the living garbage disposal

Fig.2 Components of the business costs $\mathbf{B}_{\mathbf{1}}$

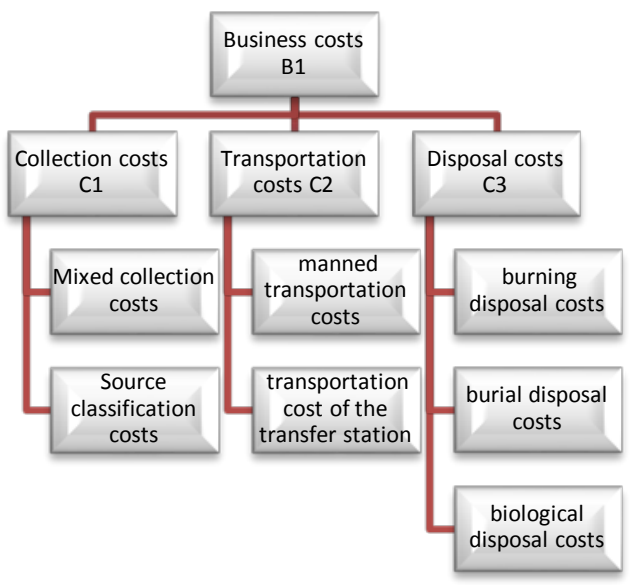

Analysis of technical costs; technical costs cover both variable costs and fixed costs, as shown in Figure 3:

Analysis of long-term social costs: covering loss incurred from water pollution; loss incurred from air pollution, loss incurred from solid waste pollution, as shown in Figure 4:

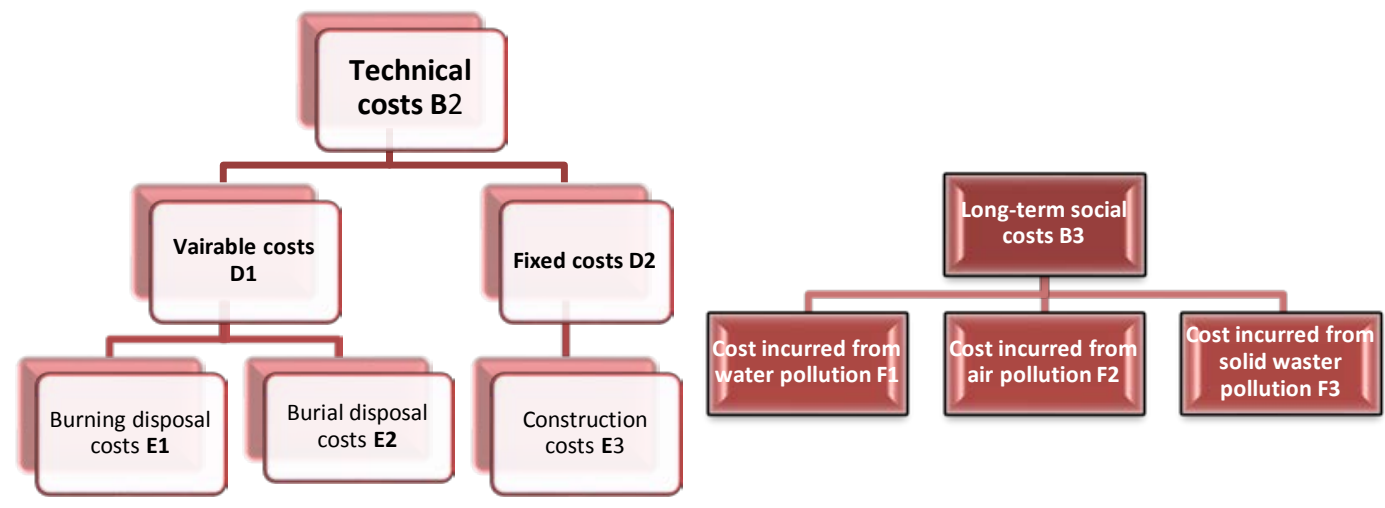

Fig.3 Components of technical costs $B_{2} \quad$ Fig.4 Components of long-term social costs $B_{3}$

\subsection{Analysis of the model}

Taking into account the different circumstances, policy makers choose a combination of different modes for garbage disposal. Therefore, on calculation of the total cost, this paper applies the superposition of the costs of different links in each mode, so as to get the total cost model of living garbage disposal in our country. The calculation equation for the total costs: $A=B_{1}+B_{2}+B_{3}$; calculation equation of business costs: $B_{1}=C_{1}+C_{2}+C_{3}$; calculation equation of the collection costs; $\mathrm{C}_{1}=\mathrm{C}_{11}+\mathrm{C}_{12}$ ( $\mathrm{C}_{11}$ for the mixed transportation costs, $\mathrm{C}_{12}$ for the source classification cost); calculation equation for the transportation cost: $\mathrm{C}_{2}=\mathrm{C}_{21}+\mathrm{C}_{22}\left(\mathrm{C}_{21}\right.$ for the manned transportation costs, $\mathrm{C}_{22}$ for the transportation cost of the transfer station); calculation equation for the disposal costs: $\mathrm{C}_{3}=\mathrm{C}_{31}+\mathrm{C}_{32}+\mathrm{C}_{33}\left(\mathrm{C}_{31}\right.$ for the burning disposal cost, $\mathrm{C}_{32}$ for the burial disposal cost, $\mathrm{C}_{33}$ 
for the biological disposal cost). Calculation equation for the technical costs: $B_{2}=D_{1}+D_{2}$; the variable costs $E_{1}$ are various government subsidies, which in the model hypothesis are described as under an ideal state. Calculation equation for the fixed costs: $D_{2}=E_{1}+E_{2}+E_{3}$ ( $E_{1}$ for costs of the burned land, $\mathrm{E}_{2}$ for costs for land filling, $\mathrm{E}_{3}$ for construction costs); calculation equation for the long-term social costs: $B_{3}=F_{1}+F_{2}+F_{3}$ ( $F_{1}$ for losses incurred from water pollution, $F_{2}$ for losses incurred from air pollution, $\mathrm{F}_{3}$ for losses incurred from solid wastes).

\subsection{Model solution}

China's total waste production analysis (2010-2015) is taken for analysis, as shown in Figure 5 below:

Fig. 5 Statistics form for China's total waste production (2010-2015)

\begin{tabular}{|l|l|l|l|l|l|l|}
\hline Year & 2010 & 2011 & 2012 & 2013 & 2014 & 2015 \\
\hline Total waste production (million tons) & 152 & 158 & 165 & 167 & 172 & 179 \\
\hline
\end{tabular}

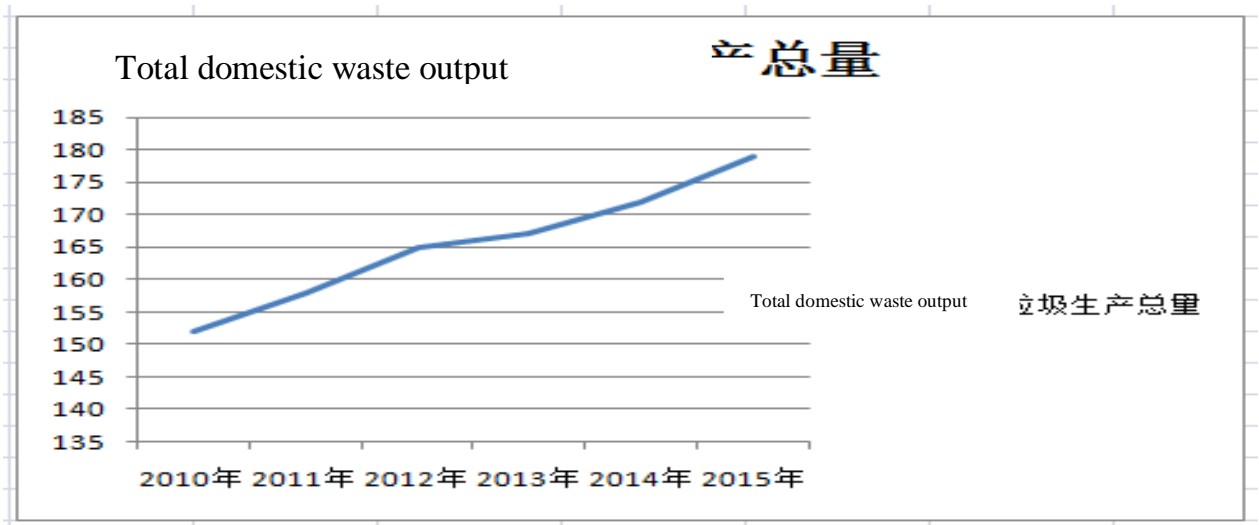

With the assumption that the amount of waste produced is directly proportional to the cost of waste disposal, an analysis of waste production is equivalent to an analysis of the cost of waste disposal in China. It can be inferred from analysis of the line chart: China's total output of garbage shows an incremental model, so the cost of garbage disposal is also gradually increasing, the cost is becoming higher and higher. The weight of each criterion on the target and the weight of each program on each criterion are determined through mutual comparison. These weights are usually qualitative in the process of human thinking, while a quantitative method of obtaining the weight is given in the analytic hierarchy process.

An integration is carried out combining the weights of the project hierarchy on the criterion hierarchy, the weights of the criterion hierarchy on the target hierarchy to finally determine the weight of the project hierarchy on the target hierarchy. An integrated calculation method should be given in the Analytic Hierarchy Process. In the Analytic Hierarchy Process, the above-mentioned procedures are to be completed combining the qualitative analysis and quantitative calculation to generate the decision results. Here we show how to compare the impact of the same hierarchy of each factor on the upper hierarchy to determine their weight in the upper hierarchy. Assume that the impact of $n$ factors $B_{1}, B_{2}, B_{3}, B_{4} \ldots B_{n}$ of a certain hierarchy on the factor $A$ of the upper hierarchy, such as in the problems of the waste disposal cost, the importance of the 3 criteria of business costs, technology costs, indirect current and long-term social costs in completing fixing the price. Each time, 2 factors $B_{i}$ and $B_{j}$ are taken, $a_{i j}$ shows the importance ratio of $B_{i}$ on $A$ to $B_{j}$ on $A$, and all the 
comparison results can be shown by means of the comparison matrix A:

$A=\left(a_{i j}\right)_{n \times n}, a_{i j}>0, a_{j i}=\frac{1}{a_{i j}}$, because in the equation $A=\left(a_{i j}\right)_{n \times n}$, features of $0 \times 1(0 \times 1), A$ is called a positive reciprocal matrix.

It is obvious that $a_{i j}=1$, with $B_{1}, B_{2}, B_{3}$ successively representing the 3 criteria of business costs, technology costs, indirect current and long-term social costs, and a paired comparison matrix can be obtained by means of the paired comparion method:

$$
A=\left\{\begin{array}{ccc}
\frac{1}{1} & 2 & 4 \\
\frac{1}{2} & 1 & 2 \\
\frac{1}{4} & \frac{1}{2} & 1
\end{array}\right\}
$$

$a_{12}=2$ means the importance ratio of the technical costs $B_{2}$ and technical costs $B_{1}$ on the overall costs $\mathrm{A}$ is $2: 1$;

$a_{13}=4$ means the importance ratio of the social costs $B_{3}$ and business costs $B_{1}$ on the overall costs $\mathrm{A}$ is $4: 1$;

$A_{23}=2$ means the importance ratio of the social costs $B_{3}$ and technical costs $B_{2}$ on the overall costs $\mathrm{A}$ is 2:1;

The positive reciprocal matrix A planning shows the weight $\omega$ of $B_{1}, B_{2}, B_{3}$ on the upper hierarchy $\mathrm{A}$, namely that $\omega$ meets $\omega \mathrm{A}=\gamma \omega$, the solution is as follows (by normalization):

$A=\left\{\begin{array}{ccc}1 & 2 & 4 \\ \frac{1}{2} & 1 & 2 \\ \frac{1}{4} & \frac{1}{2} & 1\end{array}\right\} \rightarrow A=\left\{\begin{array}{ccc}0.6 & 0.57 & 0.571 \\ 0.1 & 0.29 & 0.285 \\ 0.3 & 0.14 & 0.143\end{array}\right\}, \omega 1=\left\{\begin{array}{l}0.715 \\ 0.285 \\ 0.761\end{array}\right\} \rightarrow A \omega 1=\left\{\begin{array}{l}4.329 \\ 2.165 \\ 1.082\end{array}\right\}$

It can be obtained: $\gamma_{1}=\frac{1}{3}\left(\frac{4.329}{0.715}+\frac{2.165}{0.285}+\frac{1.082}{0.761}\right)=5.024$

The positive reciprocal matrix can be obtained through the analytic hierarchy process for $\mathrm{B}_{1}$ :

$$
B_{1}=\left\{\begin{array}{lll}
1 & 1 & \frac{2}{3} \\
1 & 1 & \frac{2}{3} \\
\frac{3}{2} & \frac{3}{2} & 1
\end{array}\right\}
$$

$b_{12}=$ means the importance ratio of collection costs $C_{1}$ and transportation costs $C_{2}$ on the business cost is $1: 1$;

$\mathrm{b}_{13}=\frac{2}{3}$ means the importance ratio of collection costs $C_{1}$ and disposal costs $C_{3}$ on the business cost is 2:3;

$\mathrm{b}_{23}=\frac{2}{3}$ means the importance ratio of transportation costs $\mathrm{C}_{2}$ and disposal costs $\mathrm{C}_{3}$ on the business cost is 2:3;

The solution is as follows (by normalization): the positive reciprocal matrix can be obtained through the analytic hierarchy process for $\mathrm{B}_{2}$ : 
$\left\{\begin{array}{lll}1 & 1 & \frac{2}{3} \\ 1 & 1 & \frac{2}{3} \\ \frac{3}{2} & \frac{3}{2} & 1\end{array}\right\} \rightarrow\left\{\begin{array}{ccc}0.3 & 0.27 & 0.267 \\ 0.3 & 0.33 & 0.333 \\ 0.4 & 0.40 & 0.41\end{array}\right\}, \omega 2=\left\{\begin{array}{c}0.28 \\ 0.32 \\ 0.40\end{array}\right\} \rightarrow A \omega 2=\left\{\begin{array}{c}0.867 \\ 0.867 \\ 1.45\end{array}\right\}$

$\mathrm{B}_{2}=\left\{\begin{array}{cccc}1 & \frac{2}{5} & \frac{2}{4} & \frac{2}{3} \\ \frac{5}{2} & 1 & \frac{5}{4} & \frac{5}{3} \\ 2 & \frac{4}{5} & 1 & \frac{4}{3} \\ \frac{3}{2} & \frac{3}{5} & \frac{3}{4} & 1\end{array}\right\}$, It can be obtained: $\gamma_{2}=\frac{1}{3}\left(\frac{0.867}{0.28}+\frac{0.867}{0.32}+\frac{1.45}{0.4}\right)=3.144$.

$b_{12}=\frac{2}{5}$ means the importance ratio of variable costs $D_{1}$ and burning costs $E_{1}$ on the technical cost is 2:5;

$b_{13}=\frac{2}{3}$ means the importance ratio of burning costs $E_{1}$ and burial costs $E_{2}$ on the technical cost is $5: 4$;

$\mathrm{b}_{14}=\frac{2}{3}$ means the importance ratio of variable costs $\mathrm{D}_{1}$ and construction costs $\mathrm{E}_{3}$ on the technical cost is 2:3;

The solution is as follows (by normalization), it can be obtained: $\gamma_{3}=\frac{1}{4}\left(\frac{0.568}{0.135}+\frac{1.421}{0.351}+\frac{1.137}{0.298}\right.$ $\left.+\frac{0.853}{0.216}\right)$

$=4.005$, the positive reciprocal matrix can be obtained through the analytic hierarchy process for $\mathrm{B}_{3}$ :

$\left\{\begin{array}{cccc}1 & \frac{2}{5} & \frac{2}{4} & \frac{2}{3} \\ \frac{5}{2} & 1 & \frac{5}{4} & \frac{5}{3} \\ 2 & \frac{4}{5} & 1 & \frac{4}{3} \\ \frac{3}{2} & \frac{3}{5} & \frac{3}{4} & 1\end{array}\right\} \rightarrow\left\{\begin{array}{cccc}0.1 & 0.14 & 0.142 & 0.1428 \\ 0.3 & 0.35 & 0.357 & 0.3571 \\ 0.3 & 0.28 & 0.285 & 0.2857 \\ 0.2 & 0.21 & 0.214 & 0.2142\end{array}\right\}$

$\omega 3=\left\{\begin{array}{l}0.135 \\ 0.351 \\ 0.298 \\ 0.216\end{array}\right\} \rightarrow A \omega 3=\left\{\begin{array}{l}0.568 \\ 1.421 \\ 1.137 \\ 0.853\end{array}\right\}, \quad B_{3}=\left\{\begin{array}{ccc}1 & \frac{7}{4} & \frac{7}{3} \\ \frac{4}{7} & 1 & \frac{4}{3} \\ \frac{3}{7} & \frac{3}{4} & 1\end{array}\right\}$

$\mathrm{b}_{12}=\frac{7}{4}$ means the importance ratio of cost incurred from water pollution $\mathrm{F}_{1}$ and cost incurred from air pollution $\mathrm{F}_{2}$ on the long-term social cost is 2:5;

$\mathrm{b}_{13}=\frac{7}{3}$ means the importance ratio of cost incurred from water pollution $F_{1}$ and cost incurred from solid waste pollution $\mathrm{F}_{3}$ on the long-term social cost is 7:3;

$\mathrm{b}_{23}=\frac{4}{3}$ means the importance ratio of cost incurred from air pollution $\mathrm{F}_{2}$ and cost incurred from 
solid waste pollution $\mathrm{F}_{3}$ on the long-term social cost is 4:3;

$$
\left\{\begin{array}{ccc}
1 & \frac{7}{4} & \frac{7}{3} \\
\frac{4}{7} & 1 & \frac{4}{3} \\
\frac{3}{7} & \frac{3}{4} & 1
\end{array}\right\} \rightarrow\left\{\begin{array}{lll}
0.5 & 0.50 & 0.496 \\
0.2 & 0.28 & 0.284 \\
0.2 & 0.21 & 0.212
\end{array}\right\}, \omega 4=\left\{\begin{array}{l}
0.520 \\
0.264 \\
0.216
\end{array}\right\} \rightarrow A \omega 4=\left\{\begin{array}{l}
1.486 \\
0.849 \\
0.637
\end{array}\right\}
$$

It can be obtained (by normalization) as follows: $\gamma_{4}=\frac{1}{3}\left(\frac{1.486}{0.520}+\frac{0.849}{0.264}+\frac{0.637}{0.216}\right)=3.008$

\section{Model evaluation}

Advantages: each problem is analyzed from a variety of influencing factors, in which the persuasiveness of the model is enhanced.

Disadvantages: out of many factors that affect the cost of waste disposal, an accurate study cannot be carried out to all factors.

\section{References}

[1] Peng Fang, Yang Ruiyan, Xiao Haijun, He Yongming. "Mathematical modeling method" [M], Beijing: Science Press, Feb, 2012.

[2] Du Xiufeng, Zhang Jian, Zhang Hongmin. "Mathematical Modeling" [M], Beijing: Beihang University Press, Aug, 2011.

[3] Fang Duanyuan, Wei Mingjun. "Guide and case analysis for mathematical modeling method" [M], Zhejiang University press, 2011. 